\begin{tabular}{c|c}
\multirow{2}{*}{ EESD'15 } & The $7^{\text {th }}$ International Conference on Engineering Education for Sustainable Development \\
\cline { 2 - 2 } & Vancouver, Canada, June 9 to 12, 2015
\end{tabular}

\title{
WHAT DO PROGRAMME CHAIRS THINK ABOUT THE INTEGRATION OF SD IN THEIR PROGRAMMES?
}

\author{
lacovos Nicolaou ${ }^{1,2}$, Eddie Conlon ${ }^{1}$ \\ ${ }^{1}$ Dublin Institute of Technology, Ireland \\ 2 iacovos.nicolaou@gmail.com
}

\begin{abstract}
This paper presents the findings of interviews with six engineering programme chairs regarding their views about the level of integration of SD in their programmes. They are part of a wider study which is examining the integration of SD in engineering programmes across three Irish Higher Education Institutions. Previous stages of the study have determined that students' knowledge and understanding about SD is inadequate due to the lack of a holistic integration of SD competencies and the focus on skills development in their programmes. The paper will explore the apparent contradiction in that most programme chairs believe that SD is integrated into their programmes despite the evidence from the previous stages of this project which suggest it is not. This contradiction can only be resolved by an exploration of their understanding of SD and their philosophy of engineering education. We conclude that they believe SD is fully integrated because they have a narrow understanding of SD and a "traditional" approach to engineering focused on the development of core engineering competencies.
\end{abstract}

\section{INTRODUCTION}

Engineering Education is a complex system involving the collaboration of various stakeholders. Crawley et al (2007) argue that students, universities, industry and society are the main stakeholders in Engineering Education for SD (EESD). Despite the aforementioned importance of universities in preparing students to become change agents there are increasing concerns that universities act more as barriers for EESD rather than as enablers (Donelly and Boyle 2006, Jones, Selby, and Sterling 2010).

Some components of the current regime in universities can act as barriers. Curriculum design supports strictly disciplinary oriented programmes with little focus on SD competencies (Lehmann et al. 2008, Lozano 2010, Nicolaou and Conlon 2013) and staff are reluctant to acknowledge the importance of SD due to their misconceptions of the concept (Boyle 2004, Dawe, Jucker, and Martin 2005, Lozano 2006). In one study characterising staffs' understanding of SD, the authors used metaphors as fundamental units of cognition for interpreting staffs' mental models of sustainability (Carew and Mitchell 2006). According to this analysis, staff has a variety of mental models for understanding sustainability. Some academics perceive sustainability as a continuous process focused on the needs of society. They have a broad view of the concept which is mediated by feedback from society. They are committed to holistic technology. This mental model is interpreted as seeing SD as a weaving concept. On the other hand some academics perceive SD as a guarding concept consisting of prescriptive technologies which focuses on the conservation of resources, waste management and the commodification of nature. They are committed to the notion of 'techno-optimism' and to traditional views that "objective experts equipped with technical knowledge are the appropriate people to initiate, control and monitor use of resources" (Carew and Mitchell 2006 p.225). The latter metaphor leads academics to see SD as an added-on tool (Sterling 2001). 
The misconception of the concept that some staff have leads them to have a narrow understanding of SD which is related to the environmental aspect of the concept (Summers, Corney, and Childs 2004, Reid and Petocz 2006, Cotton et al. 2007) and neglects the social dimension (Edvardsson Bjornberg and Skogh 2013). EESD "experts" argue that the social dimension is more relevant to SD than the environmental and the technological ones (Segalas, Mulder, and Ferrer-Balas 2012). This in association with staff's neglect of the social dimension illustrates that action is needed to improve staff's awareness of the complexity of SD. According to Mulder et al (2012) improving staff's awareness of the concept will help them acknowledge the importance of SD. Staff will then be able to see that the integration of SD in their programmes is imperative and integral to a lasting paradigm shift. If this fails then staff will see SD as a separate entity (Boks and Diehl 2006, Jones, Selby, and Sterling 2010) and will continue to treat it as an added on tool.

It is acknowledged that staff's role is critical in EESD as the senders of the message of SD (Djordjevic and Cotton 2011). Thus if their knowledge and understanding of SD is limited then the message sent is distorted and creates significant knowledge gaps and limited understanding of SD among engineering students (Carew and Mitchell 2001, Azapagic, Perdan, and Shallcross 2005, Nicolaou and Conlon 2012).

\section{SCOPE AND RATIONALE}

The work reported here is part of a wider project that is designed to examine the level of provision of EESD in seven engineering programmes in three Irish Higher Education Institutions. The programmes' disciplines are civil, mechanical, structural, building services and chemical engineering. The project has already determined that final year engineering students' knowledge and understanding of SD is inadequate with significant knowledge gaps (Nicolaou and Conlon 2012). This is a result of an insufficient provision of SD competencies which is not based on a holistic approach to EESD (Nicolaou and Conlon 2013). The social dimension of SD was inadequately addressed. The programmes do not provide the broad and general education for SD that engineers need in order to become agents of change for SD (Ashford 2010).

Given the deficiencies in the provision for EESD that have emerged from our surveys of students (Nicolaou and Conlon 2012) and our analysis of programme content (Nicolaou and Conlon 2013) and the importance of staff to EESD, as indicated above, it was decided to explore staff's knowledge of SD and their views about its integration in engineering education. In the first instance we considered a staff survey but for reasons to do with concerns relating to possible low response rates and the limitations of survey data for exploring the underlying mechanisms shaping EESD it was decided to conduct a series of in depth interviews with programme chairs (directors) who are central figures in providing academic leadership on programmes and play a central role in programme validation and accreditation events. Thus we wanted to use qualitative methods to build on, and help us understand the quantitative data that had been collected in earlier stages.

In making this decision we were influenced by Critical Realism (Scott 2007) and its emphasis on the stratified nature of reality (consisting of the real, the actual and the empirical) and the need to look "below" empirical data to the realm of the real and identify the underlying casual mechanisms which can explain events. For Critical Realism the key ontological framing device is the relationship between human action and the social context: "the relationship between structure and agency or enablement and constraint" (Scott 2000 p.3). Thus there is a need to consider individual and collective action and how they are shaped by social relations and institutional structures and culture. Critical realism also provides a social ontology which can be used to justify the combination of qualitative and quantitative methods in social research (McEvoy and Richards 2006, Scott 2007).

\section{METHODOLOGY}

The data reported here is entirely based on the collection and analysis of qualitative data through a series of interviews with programme chairs that were designed to explore the factors that impact programme 
design and programme chairs' views of SD. For the purposes of this paper we are focusing on their views about the integration of SD in their programmes and their personal understandings and beliefs about SD.

\subsection{Interview Design}

The interviews followed a structured design with a sequence of thematic areas and questions. Space and time was also left for probing and clarification of issues that the participants could raise during the discussion.

Our approach to designing the interview questions was driven by two considerations. We wanted to raise with the chairs a number of issues which had arisen from the previous stages of the project. In particular we wanted to explore the missing social dimension of SD including the ethics of SD, the focus on environmental and energy issues and the absence of any forms of interdisciplinary activity in the programmes. But we also wanted to explore these issues in light of key factors that arose in the literature which were deemed to have an effect on programme design. We wanted to encourage reflection on what the key factors shaping programme design were and how they might be constraining the implementation of EESD in the programmes under investigation. These factors included institutional policies on EESD; professional accreditation processes; commitment to EESD in programme design and staff knowledge and understanding of SD. Given the limitations of time in relation to the length of the interviews, we were concerned to address the process of programme design while at the same time seeking to understand the outcomes from earlier phases of the project. In essence it became essential to identify a number of key themes that could be addressed in an interview that would last for approximately one hour.

In light of the above considerable time was spent mapping out the key issues that had arisen to concepts and factors that had been identified in the literature. We ended up with maps similar to conceptual maps in which we were trying to link the problems we had identified with possible causal factors. As a result of this work a number of key themes were identified for the interviews. These were:

- Personal history of engagement with EESD:

- Institutional policy in relation to EESD

- $\quad$ The role of professional accreditation in shaping programme design

- $\quad$ Commitment to EESD in programme design and other factors which shaped programme design

- $\quad$ Programme content and EESD

- $\quad$ The integration of the social dimension and the ethics of $S D$

- $\quad$ The role of multidisciplinarity in their programmes

- In addition the chairs were asked to identify the key features of an engineer who wanted to contribute to $S D$ and the key attributes that a modern engineer would need.

In order to test the design and the effectiveness of the questions a pilot study was carried out that in general did not show any significant design flaws in the questions. Small adjustments in relation to question wording and placement were made.

\subsection{Data Collection and Analysis}

One hour interviews were scheduled with the selected programme chairs. The interviews were audio recorded for the purposes of transcription and analysis. One programme chair did not participate despite the several attempts to get in contact and schedule an interview.

The data analysis was carried out according to Braun's and Clark (2006) six steps framework of thematic analysis of latent themes. Initially the audio recordings were transcribed which assisted with familiarisation with the data corpus. The interview transcripts were then imported into QSR's NVivo 10 where a participant-driven coding was carried out. Then the nodes generated were merged into wider categories under parent nodes which underwent further coding to support the categorisation. The underlying themes of the categories generated were reviewed; further coding was carried out to support the identification of the themes. The themes were then reviewed and further coding was conducted to further support the latent themes. Finally a report was produced that provided a detailed account of the 
themes supported with inferences drawn from the raw data. Thematic analysis is an iterative process of continuous coding until a satisfactory level of the review of themes is reached.

The sections below present the findings about the programme chairs' views of SD and their views about the level of integration of SD in their programmes. Full anonymity of the participants was assured; hence quotes extracted from the interviews will be referenced as Participant 1, 2 etc.

\section{$4 \quad$ FINDINGS}

All programme chairs have an engineering focused education both at an undergraduate and postgraduate level. The majority of them have industrial experience prior to their academic career which has helped them to establish good links with industry that most of them still maintain.

According to them SD was not part of their education or professional development: No, it wouldn't have been in the context of actual lecturers on sustainability no, but I did qualify a long time ago and it wouldn't be as much as an issue back then. (Participant 5)

The following sections present data in relation to their understanding of SD and their views about its integration in their programmes.

\subsection{Programme chairs' opinions regarding the integration of SD in their programmes}

Prior to this study, a curriculum content investigation on the respective programmes was carried out to assess the level of integration of SD competencies. That study determined that the integration does not follow a holistic approach but isolated module attempts where the focus is on transferable skills and disciplinary elements related to the environmental dimension of the concept (Nicolaou and Conlon 2013). Although there are differences in the range of modules provided, the breadth of competencies covered remains the same among all programmes regardless of the discipline. In contrast to this finding the interviews reveal some variance between the programme chairs views about the integration of SD in their programmes.

There is a general agreement that engineering programmes follow a design that is influenced by a strict disciplinary focus on core engineering competencies and does not show an active commitment to SD.

Had the team as a whole had a series of conclaves where we decided that module would have this content based specifically on sustainability, no we didn't. (Participant 1)

The top down approach from the science foundation, the mathematics, the technology and the design theory and I suppose the design practice but then everything else is added on to the core competencies. (Participant 3)

We focus on engineering applied subjects, systems design and transferable skills (Participant 4)

According to the participants, the programmes are designed with a disciplinary focus due to the fact that vital accreditation processes by Engineers Ireland focus on assessing the provision of core engineering competencies (even when efforts are being made to expand SD content).

The last accreditation included a proposed introduction of a new stream to the mechanical engineering programme and it was a stream that was titled Sustainable Energy Systems. Of course that was talked about a little bit but the emphasis wasn't on sustainability, the emphasis was more meeting the requirements of the mechanical degree that we were saying to be the final award. So El seemed to look at the criteria irrespective of the SD title of the stream and just focus whether or not the graduates coming from that stream would equally be applicable to a mechanical engineering award. (Participant 3)

Despite the general agreement of the lack of consideration of SD in programme design, programme chairs have different views about the way SD is integrated in their programmes. One participant argues that SD is embedded in his programme

The fact is that we include in everything we do, its build in there, again it's how you define SD (Participant 5) 
Another, whose programme was designed with an active learning rationale, has showed evidence of how $\mathrm{SD}$ is actually embedded but the example focuses on a single module with an environmental focus.

For example in soil mechanics the problem that students work on in second year is creating a detention pond so that the university can have a sustainable supply of non-potable water. So they learn how to design dams to retain water, they have to determine what are the needs of the university so they decide the size of the pond needed and of course the overwriting theme is a sustainable supply of grey water. So it is there; it might not be in the center of discussion but is embedded and I think that is the answer to it (Participant 1)

Participant 2 argues that SD is "nicely addressed" across the programme.

I think that it is important that we brought the subject in first year, third year and then in the design project because it then gives that sort of umbrella system instead of saying "we have 50 modules and there is a 51st which is about sustainability. (Participant 2)

This notion of having separate modules for SD is also supported by Participant 6 .

When the participants were asked to discuss any particular focus on content for SD, the majority of them identified sustainability elements that are directly related with the discipline of each programme.

The programme was driven around the subject areas and we had three themes energy as it applies to the civil engineer, environment and structure and infrastructure (Participant 1)

Energy I suppose. Energy and water would be the main two for us. (Participant 4)

It is worth noting that none of the participants mentioned, without prompting, the level to which the social dimension is addressed by their programmes. When they were asked, the participants' responses suggest that the social dimension is not well integrated in their programmes.

There is a little bit about engineers and society, what is their role but just the basic understanding. (Participant 2)

The closest to it I don't think it is delivered. I don't think that the students have an explicit exposure to the social dimension of SD. (Participant 3)

Interestingly, when they were asked, the majority of the participants did not identify any specific weaknesses in relation to how SD is addressed in programme design and integrated in content.

To be honest no, I think there is a nice balance. (Participant 6)

Nonetheless one programme chair was critical about the extent to which areas of SD are addressed in his programme. He claims that SD solutions are always seen as technical solutions:

Touchdown, it's very much a case of why will we do this? Because of $\mathrm{CO} 2$ emissions we need to reduce that we have limited resources and then there is your justification and then its straight into the technology. (Participant 3)

What is interesting about this response is that it comes from the chair with perhaps the most advanced understanding of SD. The evaluations of the other Chairs are also related to their views of SD which will be explored in the next section.

\subsection{Programme chairs' views of SD}

Programme chairs views about the integration of SD vary and differ as does their understanding of SD. Interestingly some of the programme chairs acknowledge that SD is a wide concept that incorporates various different aspects which however is difficult to define.

So it's a difficult equation and I wouldn't put sustainability so much in terms of CO2 and GHG production, I think it's a much wider issue than that (Participant 2)

So while they may believe there is more to it than environmental and resource issues they were not always able to identify what the additional elements were. Participant 3 , who had the broadest understanding of what SD is, argued that:

One of the biggest difficulties that I see is perceptions of what SD is. (Participant 3) 
This is well illustrated in the majority of the programme chairs responses which describe SD as a concept that relates economic development with environmental considerations that are mainly focused on energy, materials and resource issues.

By saving money you are saving materials which is linked to sustainability (Participant 1)

I suppose its development that makes reasonable demands on the resources that we have so that the resources are not depleted, particularly finite resources (Participant 7)

There is also evidence indicating that some programme chairs also see SD as an ongoing process as expressed in the Brundtland Report.

People describe sustainability as this generation not leaving a bill to the next one (Participant 4) Just trying to make sure that we use the resources of the planet and that we don't overuse them and that they will still be there for the generations to come. (Participant 6)

While this is an acknowledgment of the role of intergenerational equity the focus is on resource use. There was no evidence that the Chairs saw intra-generational equity as a key feature of SD.

One programme chair's definition deviates from the rest as he saw SD as a three pillar concept.

I would see $S D$ as being where change and creation occur due to human endeavour that can continue indefinitely without complete depletion of any resources that are non-renewable under three pillars of environment, society and culture and economics or commerce. (Participant 3)

Although Participant 3 had an engineering education like the rest of the participants, his personal interest about SD and his involvement in the design of a postgraduate programme predominately focused on SD has given him the opportunity to improve his awareness of it.

Since I have been working in the educational sphere I have been heavily involved in a master's programme, a collaborative programme with two other institutes that's focused predominately in $S D$, it's actually a masters in sustainability technology and innovation. So I have been bit more of an awareness based on that compared to my previous background. (Participant 3)

Programme chairs were also asked their opinion about the characteristics that engineers should have in order to contribute to SD. Their views show a variance which is influenced by their own understanding of the concept.

All the participants argue that engineers for SD should have an awareness of the concept without though being specific.

First and foremost awareness (Participant 3)

They have to know about it in the first instance (Participant 6)

Although ethics and values were identified as an important characteristic, those where limited to engineers' professional conduct in relation to materials, safety and the environment while the social context of their practice was identified to a lesser extent.

I think they would need to have a strong ethical set of moral values of what they create has an impact on everyone's lives. I think those include a global perspective on things, they consider the materials they use, are they aware exact how much energy is required to manufacture a cubic meter of concrete or a universal beam section (Participant 1)

There is a much more organised and systematic way now approaching problems like the hazards to the environment and safety. (Participant 2)

They will deal with things in a professional manner (Participant 4)

The discussion of ethical issues had a focus on micro ethical issues focused on design issues related with material use and safety while an awareness or knowledge of macro issues, such as social equity, were not mentioned as important attributes for engineers.

Most of the participants' views of the characteristics of engineers for SD are related with the necessity for engineers to be able to apply specific tools and have skills such as systemic thinking.

They would need to be rigorous thinkers (Participant 1)

The concept of LCA is important (Participant 2) 
For us the issue is energy, not much energy as carbon production more strictly speaking is low carbon design rather than low energy design. (Participant 4)

The majority of them argue that engineers are problem solvers without any reference to the role of engineers as problem framers (Donelly and Boyle 2006).

It is worth noting that the majority of the programme chairs argue strongly that the role of their programmes is to educate employable graduates that will have the competencies needed to work in industrial environments which include some elements related to SD.

It is an issue for SD but for us is also an issue of job opportunities for graduates and so this is an area that we need to integrate more content. (Participant 2)

The programme chairs views about the characteristics of modern engineers are limited to the applied tools and skills that are directly related with their employability. The programme chairs neglect the importance of engineers understanding the social context of their practice and the complexity of the socio-economic systems in which engineering is applied (Gößling-Reisemann and von Gleich 2007).

\section{DISCUSSION}

The findings suggest that there are two latent themes informing responses across a number of topics explored in the interviews. The first one is programme chairs views of SD and the second their views of engineering education. It is evident that the former is impacting the latter. The participants have particular views about SD that leads them to believe that SD is mainly an environmental concept (Cotton et al. 2007). This misconception is influencing their evaluation of the extent to which SD is integrated into their programmes; their lack of engagement with the social dimension; and their identification of attributes that engineers who want to contribute to SD should have.

Their descriptions of the concept suggest that the majority of them see SD as a guarding concept which is focused on energy issues and environmental protection and supports a disciplinary emphasis. Only one participant was able to describe SD as a weaving concept that encourages awareness and puts the needs of society at the center of engineering (Carew and Mitchell 2006). In relation to the latter it is clear that personal interest and professional development opportunities related to SD are a vital component in improving staff's awareness about the concept since none of them have any formal education for SD and most of them were industry practitioners before their academic career.

Although the majority of them claim that SD is embedded, the data suggest that they see the concept as a separate entity and thus treat it as a complementary consideration in their teaching (Reid and Petocz 2006, Jones, Selby, and Sterling 2010). This leads to a variance between the programme chairs claims and the findings of the curriculum content investigation (Nicolaou and Conlon 2013) which preceded this study. It is clear that SD is not a priority despite the explicit call for integrating SD at every level of education by the Irish National Strategy for SD (DOE 2007).

The focus on core engineering competencies is prevalent in the programmes. This is reinforced by El's accreditation criteria which support the design of discipline specific programmes that focus on engineering competencies and transferable skills. All respondents identified $\mathrm{El}$ as the most significant influence on the design of their programmes. Having the accreditation body supporting the design of engineering programmes that do not holistically consider SD suggest that the current regime of engineering education is unlikely to quickly undergo radical change (Winberg 2008). Kember (1997) argue that staffs' allegiance is primarily with their disciplinary communities and its traditional practices. This study shows that these practices support professional standards and employability which, according to Jamison (2013), are key components of a market driven model of engineering education which supports a weak approach to sustainability (Lucena, Schneider, and Lyedens 2010). On the contrary EESD requires a multidisciplinary holistic integration of SD competencies (Svanstrom, Lozano-Garcia, and Rowe 2008). This may need to be underwritten by a socially driven model of education that would value public service, form engineers as change agents and encourage "in context" forms of learning giving attention to the social and cultural context of engineering (Jamison 2013). Thus we can conclude 
that a key causal mechanism explaining the current regime of EESD in the programmes under study is the commitment to a particular ideology of engineering education which excludes its social dimension and situates SD at the nexus between the environmental and economic dimension of the concept.

\section{Acknowledgements}

The authors would like to thank the programme chairs who agreed to participate in this study.

\section{References}

Ashford, N. 2010. "Major challenges to education for sustainable development: can the current nature of institutions of Higher Education hope to educate the change agents needed for Sustainable Development?" ERSCP and EMU Conference on Knowledge Collaboration and Learning for Sustainable Development, Delft, The Netherlands, 25-29 Oct.

Azapagic, A., S. Perdan, and D. Shallcross. 2005. "How much do engineering students know about sustainable development? The findings of an international survey and possible implications for the engineering curriculum." European Journal of Engineering Education 30 (1):1-19.

Boks, C., and J.C. Diehl. 2006. "Integration of sustainability courses: experiences in industrial engineering design." Journal of Cleaner Production 14 (9-11):932-939.

Boyle, C. 2004. "Considerations on educating engineers in sustainability." International Journal of Sustainability in Higher Education 5 (2):147-155.

Braun, V., and V. Clarke. 2006. "Using thematic analysis in psychology." Qualitative Research in Psychology 3 (2):77-101.

Carew, A. L, and C A Mitchell. 2001. "What do engineering students need to know, think or feel to understand sustainability?" 6th World Congress of Chemical Engineering, Melbourne, Australia, 23-27 September.

Carew, A.L., and C.A Mitchell. 2006. "Metaphors used by some academics in Australia for understanding and explaining sustainability." Environmental Education Research 12 (2):217-231.

Cotton, D R E, M F Warren, O Maidoroba, and I Bailey. 2007. "Sustainable Development: higher education and pedagogy: a study of lecturers' beliefs and attitudes." Environmental Education Research 13 (5):579-597.

Crawley, E, J Malmqvist, and S Ostlund. 2007. Rethinking Engineering Education: The CDIO Approach.

USA: Springer.

Dawe, G., R. Jucker, and S. Martin. 2005. Sustainable Development in Higher Education: Current Practices and Future Developments. Higher Education Academy.

Djordjevic, A., and D. R. E. Cotton. 2011. "Communicating the sustainability message in higher education institutions." International Journal of Sustainability in Higher Education 12 (4):381-394.

DOE, Department of Education and Skills. 2007. Developing a National Strategy for Education for Sustainable Development.

Donelly, R, and C Boyle. 2006. "The Catch-22 of Engineering Sustainable Development." Envronmental Engineering 132 (2):149-155.

Edvardsson Bjornberg, K., and I.B. Skogh. 2013. "Integrating social sustainability into the engineering curriculum at the Royal Institute of Technology (KTH): a pilot study." EESD'13 "Rethinking the Engineer", Cambridge, UK.

Gößling-Reisemann, Stefan, and Arnim von Gleich. 2007. "Training Engineers for Sustainability at the University of Bremen." International Journal of Engineering Education 23 (2):301-308.

Jamison, Andrew. 2013. The Making of Green Engineers: Sustainable Development and the Hybrid Imagination: Morgan \& Claypool Publishers.

Jones, Paula, David Selby, and Stephen Sterling. 2010. Sustainability Education: Perpesctives and practice accross Higher Education: Earthscan.

Kember, D. 1997. "A reconceptulisation of the research into university academics' conceptions of teaching." Learning and Instruction 7:255-275.

Lehmann, M, P Christensen, X Du, and M Thrane. 2008. "Problem-oriented and project based learning (POPBL) as an innovative learning strategy for sustainable development in engineering education." European Journal of Engineering Education 33 (3):283-295. 
Lozano, R. 2006. "Incorporation and institutionalization of SD into universities: breaking through barriers to change." Cleaner Production 14:787-796.

Lozano, R. 2010. "Diffusion of sustainable development in universities' curricula: an empirical example from Cardiff University." Journal of Cleaner Production 18:637-644.

Lucena, Juan, Jen Schneider, and Jon A. Lyedens. 2010. Engineering and Sustainable Community Development. Edited by Caroline Baillie. USA: Morgan and Claypool Publishers.

McEvoy, Phil, and David Richards. 2006. "A critical realist rationale for using a combination of quantitative and qualitative methods." Journal of Research in Nursing 11 (1):66-78.

Mulder, F. Karel, Jordi Segalas, and Didac Ferrer-Balas. 2012. "How to educate engineers for/in sustainable development. Ten years of discussion, remaining challenges." International Journal of Sustainability in Higher Education 13 (3):211-218.

Nicolaou, lacovos, and Eddie Conlon. 2012. "What do final year engineering students know about sustainable development?" European Journal of Engineering Education 37 (3):267-277. doi: 10.1080/03043797.2012.681863.

Nicolaou, lacovos, and Eddie Conlon. 2013. "The integration of sustainable development competencies in Irish Engineering Education: Findings of a curriculum content investigation of four engineering programmes." EESD'13 "Rethinking the Engineer", University of Cambridge, UK.

Reid, A, and P Petocz. 2006. "University lecturers' understanding of sustainability." Higher Education 51:105-123.

Scott, David. 2007. "Resolving the quantitative-qualitative dilemma: a critical realist approach." International Journal of Research and Method in Education 30 (1):3-17.

Segalas, J., K.F. Mulder, and D. Ferrer-Balas. 2012. "What do EESD "experts" think sustainability is? Which pedagogy is suitable to learn it?: Results from interviews and Cmaps analysis gathered at EESD 2008." International Journal of Sustainability in Higher Education 13 (3):293-304.

Sterling, S. 2001. Sustainable Education. Re-visioning Learning and Change. Bristol: Schumacher Society, Green Books.

Summers, M, G Corney, and A Childs. 2004. "Student teachers' conceptions of sustainable development: the starting points for geographers and scientists." Educational Research 46 (2):163-182.

Svanstrom, M., F. J. Lozano-Garcia and D. Rowe. 2008. "Learning Outcomes for sustainable development in higher education." International Journal of Sustainability in Higher Education 9 (3):339351.

Winberg, Christine. 2008. "Teaching engineering/engineering teaching: interdiscipplinary collaboration and the construction of academic identities." Teaching in Higher Education 13 (3):353-367. 